\title{
Efecto de la exposición y la toposecuencia sobre actividades biológicas del suelo en bosque relicto del centro-sur de Chile
}

\author{
Influence of slope and orientation on biological activities of a relict temperate forest from \\ South-Central Chile
}

\author{
Francisco Reyes ${ }^{\text {a, }}$, Alexis Lillo ${ }^{\text {a }}$, Nelson Ojeda ${ }^{\text {b }}$, Mauricio Reyes ${ }^{\text {b }}$, Marysol Alvear ${ }^{\text {a* }}$ \\ *Autor de correspondencia: ${ }^{a}$ Universidad de La Frontera, Facultad de Ingeniería, Ciencias y Administración, Departamento de \\ Ciencias Químicas y Recursos Naturales, Scientifical and Technological Bioresource Nucleus, BIOREN, Avenida Francisco Salazar \\ 01145, casilla 54-D, Temuco, Chile, tel.: 56-45-325438, fax 56-45-325440, malvear@ufro.cl \\ b Universidad de La Frontera, Facultad de Ciencias Agropecuarias y Forestales, Departamento de Ciencias Forestales, \\ Temuco, Chile.
}

\begin{abstract}
SUMMARY
Catastrophic disturbances of forest ecosystems are natural and anthropogenic phenomena that promote the natural dynamics of biocenosis and biogeochemical processes, and are the main causes of landscape fragmentation. The aim of this study was to evaluate the effect of orientation and toposequential positions on some biological activities in a relict forest community of LapagerioAextoxiconetum during two seasons. Soil samples were collected from an Andisol $(0-15 \mathrm{~cm})$, for each toposequential position (high, medium and low slope) of a forest with orientation northeast and southwest in summer and winter. The parameters evaluated were: fluorescein diacetate hydrolysis, carbon and nitrogen biomass and activity of six enzymes related to microbiological activity: carboximethylcellulase, $\beta$-glucosidase, manganese peroxidase, urease, acid phosphatase and arylsulfatase. The results indicate that the high slope with northeast orientation showed most favourable conditions on biological activities. In turn, orientation had direct effects on the evaluated biological activities, mostly significant, due to variation in soil moisture, temperature, $\mathrm{pH}$, organic matter content and nutrient availability. Urease was the only enzyme with higher activity levels in summer, because of increase in soil temperature. Biological activities were affected by seasonality, being significantly higher in winter; the differences observed for different biological parameters are attributed to microclimates that were generated under the tree canopy and mulch.
\end{abstract}

Key words: temperate forests, toposequence, microbial biomass, soil enzyme activities.

\section{RESUMEN}

Las alteraciones catastróficas en ecosistemas boscosos son fenómenos naturales o antropogénicos que promueven la dinámica natural de la biocenosis y los procesos biogeoquímicos, y constituyen la principal causa de fragmentación del paisaje. El objetivo de este estudio fue evaluar el efecto de la exposición y la toposecuencia sobre algunas actividades biológicas del suelo de un bosque relicto de la comunidad Lapagerio-Aextoxiconetum, en dos estaciones del año. Se recolectaron muestras de suelo $(0-15 \mathrm{~cm})$, con características de Andisol por cada uno de los niveles toposecuenciales (laderas alta, media y baja) con exposición noreste y suroeste, en verano e invierno. Los parámetros evaluados fueron: hidrólisis de la fluoresceína diacetato, carbono y nitrógeno en la biomasa microbiana y la actividad de seis enzimas relacionadas con la actividad microbiológica: carboximetilcelulasa, $\beta$-glucosidasa, manganeso peroxidasa, ureasa, fosfatasa ácida y arilsulfatasa. Los resultados obtenidos indican que la ladera alta con exposición noreste presentó condiciones más favorables para las actividades biológicas. La exposición tuvo efectos directos sobre las actividades biológicas, mayoritariamente significativos, debido a la variación del suelo en humedad, temperatura, $\mathrm{pH}$, contenido de materia orgánica y disponibilidad de nutrientes. La ureasa fue la única enzima con mayor actividad en verano, debido al aumento de la temperatura del suelo. Las actividades biológicas fueron afectadas significativamente por la estacionalidad, siendo mayores en invierno, donde las diferencias observadas para los distintos parámetros biológicos se atribuyeron a condiciones de microclima que se generan bajo el dosel arbóreo y el mantillo.

Palabras clave: bosques templados, toposecuencia, biomasa microbiana, actividad enzimática del suelo.

\section{INTRODUCCIÓN}

Las alteraciones catastróficas de los ecosistemas boscosos son fenómenos de origen natural o por la acción humana que promueven la dinámica natural de la biocenosis y los procesos biogeoquímicos. Así mismo, las perturbaciones naturales, fragmentación del paisaje y el manejo fo- restal, afectan drásticamente los reservorios de carbono y alteran los ciclos biogeoquímicos en ecosistemas boscosos (Armesto et al. 2009).

La vegetación existente en la Depresión Intermedia de la provincia de Cautín, región de La Araucanía, constituye bosques templados, cuya distribución es reducida como consecuencia de la acción antropogénica, permaneciendo 
sólo algunos relictos los cuales poseen importancia ecológica y científica.

En estas áreas de distribución fragmentada del bosque existe un contraste climático, edáfico y de composición florístico entre las laderas de exposición ecuatorial y polar. La exposición de las laderas y las condiciones microclimáticas a lo largo de la toposecuencia afectan las propiedades físico-químicas del suelo, tales como el contenido de materia orgánica, el pH y la humedad (Burke 2003). También se observa un efecto de la toposecuencia sobre el desarrollo de los suelos, de tal modo que un suelo ubicado en la parte alta de una ladera generalmente presenta un menor grado de evolución que el de la parte media y baja de la misma, lo que se expresa en un perfil menos profundo, una menor disponibilidad de agua y nutrientes para la vegetación y, por consiguiente, una menor capacidad sustentadora de fitomasa (Kang et al. 2009). Los cambios estacionales en diversos parámetros físico-químicos, tales como humedad, temperatura, $\mathrm{pH}$ y disponibilidad de sustratos, principalmente, impactan la biomasa microbiana y la actividad enzimática de la microbiota (Alvear et al. 2007, 2008).

Diversos autores (Trasar-Cepeda et al. 2000, Alvear et al. 2008) han propuesto una serie de parámetros biológicos, considerados útiles como indicadores edáficos en un amplio rango de situaciones ecológicas para valorar la calidad de los suelos; entre ellos, la hidrólisis de la fluoresceína diacetato es utilizada como un simple y adecuado método para la medida de la actividad microbiana total del suelo. El carbono y nitrógeno en la biomasa microbiana sirven para determinar el tamaño aproximado de la comunidad microbiana presente en el suelo (Alvear et al. 2007).

Dentro de la flora microbiana se encuentran las enzimas, cuyo conocimiento en el nivel de actividad en el suelo permite estimar los cambios en la descomposición de la materia orgánica. Las enzimas hidrolíticas tienen un importante rol en la degradación de los residuos vegetales, y por tanto son fundamentales en el ciclo de los nutrientes más importantes (carbono, nitrógeno y fósforo) para el desarrollo de los vegetales. Así, la carboximetilcelulasa indica el nivel de actividad de las endocelulasas o las enzimas capaces de hidrolizar enlaces glucosídicos al interior de las moléculas cristalinas de celulosa. La $\beta$-glucosidasa, está involucrada en la degradación de la celulosa (Turner et al. 2002). La enzima manganeso peroxidasa es altamente eficiente en la degradación de la lignina. El sustrato primario es manganeso (II) que se oxida a manganeso (III) (Hofrichter 2002). Las fosfatasas hidrolizan los compuestos orgánicos del fósforo, pirofosfatos, metafosfatos y polifosfatos presentes en el suelo. La actividad ureasa participa en el proceso de hidrólisis de la urea, esta enzima es secretada por microorganismos, plantas y animales, y utilizada como indicador de calidad y manejo sustentable del suelo (Gil-Sotres et al. 1992). La arilsulfatasa es una enzima que participa en el proceso de hidrólisis del éstersulfato de la materia orgánica del suelo liberando azufre, elemento esencial, como ion sulfato $\left(\mathrm{SO}_{4}^{-2}\right)$.

Las enzimas están estrechamente relacionadas con las propiedades físicas, químicas y biológicas por lo que permiten monitorear el funcionamiento del suelo. Los estudios que caracterizan de forma general a los suelos forestales, cada vez requieren de mayor información para determinar el funcionamiento del ecosistema edáfico ya que son indicadores de la calidad y el equilibrio que existe en el medio (Trasar-Cepeda et al. 2000, Valenzuela et al. 2001, Alvear et al. 2008).

Una evaluación de la diversidad biológica, no solo debe estar basada en la identificación y cuantificación de los microorganismos involucrados, sino que es esencial investigar el rol funcional para definir el significado de la diversidad microbiana (Valenzuela et al. 2001). A su vez, los microorganismos edáficos son considerados como la fracción más activa de la materia orgánica, con tiempos de recambio muy cortos, de días a meses (Alvear et al. 2007).

Las distintas posiciones toposecuenciales y exposiciones en la ladera, así como las variaciones estacionales durante el año, inciden en las fluctuaciones de las variables medioambientales como temperatura, humedad y tipo de vegetación; ellas, a su vez, afectan la actividad de los microorganismos del suelo, los que regulan la disponibilidad de nutrientes en el sistema suelo. El objetivo de este estudio es evaluar el efecto de la exposición y toposecuencia en dos estaciones del año sobre la actividad microbiológica y de seis enzimas relacionadas a los ciclos biogeoquímicos de un suelo con características de Andisol, de un bosque templado del centro-sur de Chile.

\section{MÉTODOS}

Área de estudio. El estudio se realizó en el predio Rucamanque, ubicado en los $38^{\circ} 39^{\prime}$ latitud Sur y $72^{\circ} 35^{\prime}$ longitud Oeste, en la comuna de Temuco, Chile y posee una superficie de 435 ha. La vegetación original está formada por las comunidades boscosas de olivillo (Lapagerio-Aextoxiconetum punctatii) y roble-laurel-lingue (NothofagoPerseetum), la primera en el fondo y parte inferior de las laderas y la segunda, en la parte superior. El predio posee una topografía de relieve montañoso e irregular, por lo que las laderas cubiertas por las comunidades boscosas presentan pendientes variadas en extensión e inclinación. La comunidad boscosa estudiada es mixta adulta de olivillo (Aextoxicon punctatum R. et P.), roble (Nothofagus obliqua (Mirb.) Oerst.), ulmo (Eucryphia cordifolia Cav.), laurel (Laurelia sempervirens R. et P.) y lingue (Persea lingue R. et P.) perteneciente al tipo forestal roble-raulí-coigüe, subtipo remanentes originales (Donoso 1981).

El clima es templado húmedo, con una precipitación anual de $1.400 \mathrm{~mm}$. La altitud media del predio es de 376 m s.n.m., con predominancia de suelos con características de Andisol, en las zonas medias y altas. La temperatura media es de $12{ }^{\circ} \mathrm{C}$, con uno o dos meses de sequía en verano. Durante la época de estudio la precipitación fue 
de $42,4 \mathrm{~mm}$ y $177 \mathrm{~mm}$, con temperaturas promedio de $17,8^{\circ} \mathrm{C}$ y de $8,6^{\circ} \mathrm{C}$ en verano e invierno, respectivamente.

Antecedentes dasométricos. Los estadígrafos de los inventarios forestales se obtuvieron mediante un diseño de muestreo aleatorio simple, con parcelas de $500 \mathrm{~m}^{2}$ de forma rectangular $(25 \times 20)$, con el eje principal de la parcela orientado de norte a sur. Para la ladera de exposición NE se establecieron 17 parcelas correspondientes a una intensidad de muestreo del 4,6\% de su superficie total, y para la ladera SO, se establecieron 23 parcelas, equivalentes a una intensidad de muestreo del $4 \%$ de su superficie total. La ladera con exposición SO tiene una densidad de $694 \pm$ 152 árboles ha ${ }^{-1}$, con cobertura de dosel de $73 \%$, en tanto la ladera con exposición NE es de $718 \pm 140$ árboles ha ${ }^{-1}$, con una cobertura de dosel de $88 \%$. En ambos rodales se presentó una distribución diamétrica asimétrica negativa de 5 a $110 \mathrm{~cm}$, presentando la ladera SO una mayor concentración de individuos en clases diamétricas de 5 a $15 \mathrm{~cm}$, en tanto en la ladera NE, los individuos se concentran en las clases diamétricas entre 15 y $45 \mathrm{~cm}$.

Recolección de las muestras de suelo. Las muestras fueron recolectadas desde dos laderas con exposiciones opuestas: exposición noreste (NE) con una pendiente media de $52 \%$ y exposición suroeste $(\mathrm{SO})$ con una pendiente media de $33 \%$. Se recolectaron tres muestras compuestas de suelo por cada uno de los niveles toposecuenciales (ladera alta, ladera media y ladera baja) en verano e invierno del año 2006, hasta los $15 \mathrm{~cm}$ de profundidad, removiendo la capa de mantillo. Las muestras fueron tamizadas con una abertura de malla de $2 \mathrm{~mm}$ y se guardaron en bolsas de plástico isotérmicas a $4{ }^{\circ} \mathrm{C}$ hasta su posterior análisis. Todos los resultados fueron calculados en peso seco $\left(105^{\circ} \mathrm{C}\right)$.

Análisis de suelo. La determinación de la temperatura del suelo, considerando la variación diurna y anual de la misma, se realizó a una hora cercana al mediodía, en cada una de las toposecuencias estudiadas y en ambas estaciones, utilizando un geotermómetro a $15 \mathrm{~cm}$ de profundidad. En las mismas instancias se colectaron muestras para determinar la humedad del suelo, la que se obtuvo para cada muestra a partir del factor de peso seco $\left(105^{\circ} \mathrm{C}\right)$. El análisis químico de fósforo disponible, potasio y azufre disponible, $\mathrm{pH}$ en agua, materia orgánica, y los cationes intercambiables calcio, magnesio, sodio, potasio y aluminio, saturación de aluminio, capacidad de intercambio catiónico efectiva, suma de bases del suelo se realizó según la norma chilena descrita por Sadzawka et al. (2004). Para la hidrólisis de la fluoresceína diacetato se utilizó la metodología descrita por Alvear et al. (2008); los resultados se expresaron como $\mu \mathrm{g} \mathrm{g}^{-1} \mathrm{~h}^{-1}$ de fluoresceína. El carbono y el nitrógeno en la biomasa microbiana se determinaron según el procedimiento de fumigación-extracción de Vance et al. (1987). Para medir la carboximetilcelulasa se utilizó el método de Schinner y von Mersi (1990); la actividad carboximetilcelulasa se expresó en $\mu$ moles $\mathrm{g}^{-1} \mathrm{~h}^{-1}$ de glucosa. La $\beta$-glucosidasa, fosfatasa ácida y arilsulfatasa se evaluó según Alvear et al. (2008); la actividad de estas enzimas se expresó en $\mu$ moles $\mathrm{g}^{-1} \mathrm{~h}^{-1}$ de $p$-nitrofenol (PNF). En el caso de la manganeso peroxidasa se procedió según la metodología descrita por Diez et al. (2006); la actividad manganeso peroxidasa se expresó en $\mu$ moles $\mathrm{g}^{-1} \mathrm{~min}^{-1}$ de manganeso (III); se utilizó el coeficiente de extinción molar $6,5 \mathrm{mM}^{-1} \mathrm{~cm}^{-1}$. La ureasa se obtuvo mediante la metodología descrita por Gil-Sotres et al. (1992); la actividad de la enzima se expresó en $\mu$ moles $\mathrm{g}^{-1} \mathrm{~h}^{-1}$ de $\mathrm{NH}_{3}$. Todas las determinaciones se hicieron en triplicado.

Diseño experimental. Se planteó como un diseño factorial $3 \times 2$, mediante un muestreo aleatorio dirigido. Se realizó una comparación múltiple entre las distintas posiciones toposecuenciales de una ladera y entre cada posición fisiográfica correspondiente entre ambas exposiciones, en cada estación indicada, y a nivel global comparando las exposiciones correspondientes entre cada estación. La actividad microbiana quedó representada por la hidrólisis de la fluoresceína diacetato y el carbono y nitrógeno en la biomasa microbiana. La actividad enzimática consideró carboximetilcelulasa, $\beta$-glucosidasa, manganeso peroxidasa, fosfatasa ácida, ureasa y arilsulfatasa. Las propiedades físico-químicas del suelo evaluadas fueron: fósforo, potasio y azufre disponible, $\mathrm{pH}$ en agua, materia orgánica, y los cationes intercambiables calcio, magnesio, sodio, potasio y aluminio, saturación de aluminio, capacidad de intercambio catiónico efectiva, suma de bases, humedad y temperatura.

Análisis estadístico. Se aplicó la prueba KolmogorovSmirnov sobre las variables de estudio para evaluar supuestos de normalidad. A las variables que cumplieron con tal supuesto se les realizó una prueba paramétrica (ANDEVA) para determinar la significancia de las interacciones y la comparación de medias mediante la prueba de Tukey. A las variables que no cumplieron con la normalidad se les realizó la prueba no paramétrica de Kruskal-Wallis. Todos estos supuestos y pruebas se validaron con un nivel de significancia del $95 \%$. Se realizó el análisis de correlación de Pearson entre todas las variables biológicas, comparando entre el factor exposición NE y SO, y comparando el factor estación verano e invierno, para observar la relación entre las variables según estos factores. Para realizar estos análisis se utilizó el programa estadístico SPSS versión de prueba 11.0 para Windows.

\section{RESULTADOS}

Propiedades físico-químicas. La temperatura media del suelo no presentó efectos significativos de la exposición ni de la toposecuencia. Sólo se observaron efectos significativos $(P<0,05)$ entre estaciones, alcanzándose una mayor temperatura media en verano con un valor de $8,5^{\circ} \mathrm{C}$. 
La humedad del suelo sólo presentó efectos significativos entre las exposiciones, con un promedio de $41,2 \%$ en la exposición SO y 46,6 \% en la NE (cuadro 1).

Para las variables materia orgánica, fósforo, potasio, magnesio, potasio intercambiable, aluminio, saturación de aluminio, la capacidad de intercambio catiónico efectiva y suma de bases no se encontraron efectos significativos para ninguno de los factores analizados. La saturación de aluminio permaneció en bajas concentraciones en ambas estaciones (cuadro 1).

Los valores de $\mathrm{pH}$ señalan que los suelos son moderadamente ácidos, y variaron de $6 \pm 0,2$ en verano a 5,6 \pm 0,2 en invierno, existiendo efectos significativos de las estaciones. En cambio, los valores de $\mathrm{pH}$ se mantuvieron homogéneos en los factores de toposecuencia y exposición.

La disponibilidad de azufre disminuyó significativamente desde la ladera alta hacia la ladera media. Sin embargo, no se detectaron diferencias significativas entre la ladera media y la ladera baja. Se presentaron diferencias de disponibilidad de azufre en la exposición, con mayores valores en el SO. No se observaron diferencias en la estacionalidad.

Los elementos calcio y sodio no presentaron efectos significativos para los factores de toposecuencia y exposición. Las diferencias se centraron en la estacionalidad, registrándose los mayores valores en invierno.

Los resultados de los análisis de varianza obtenidos con la interacción de factores no entregaron efectos significativos para ninguno de los parámetros físico-químicos (cuadro 1).

Biomasa microbiana y actividades enzimáticas. La hidrólisis de la fluoresceína diacetato mostró efectos significativos en la exposición y la toposecuencia (cuadro 2). En las interacciones dobles y la interacción de los tres factores se observaron efectos significativos. Por posición toposecuencial, en verano los mayores niveles de actividad se observaron en la ladera alta de ambas exposiciones, con valores de 73,74 $\mu \mathrm{g} \mathrm{g}^{-1} \mathrm{~h}^{-1}$ de fluoresceína en el NE y 76,12 $\mu \mathrm{g} \mathrm{g}^{-1} \mathrm{~h}^{-1}$ de fluoresceína en el SO. En invierno, la baja actividad se observó en la exposición SO con valores directamente proporcionales a la toposecuencia (con mayor valor en ladera alta y menor en la baja). El contenido de carbono en la biomasa microbiana presentó efectos significativos en la estacionalidad, con mayores valores en invierno. La exposición sólo mostró efectos significativos $(P=0,027)$ en la exposición NE en interacciones con la toposecuencia o la estacionalidad. El nitrógeno en la biomasa microbiana no mostró efectos significativos en ninguno de los factores evaluados ni en sus interacciones, a excepción de la interacción de los tres factores, con una clara diferencia en la ladera baja, exposición SO (174,1 $\mathrm{gg} \mathrm{g}^{-1}$ de nitrógeno).

En la estacionalidad se observaron efectos significativos para la actividad carboximetilcelulasa y fosfatasa ácida (cuadro 2). En la exposición no se observaron efectos significativos en manganeso peroxidasa y ureasa. En la interacción de los factores, se observaron efectos significativos en la mayoría de las enzimas evaluadas, a excepción de la $\beta$-glucosidasa y arilsulfatasa en la interacción de estacionalidad y ladera. En la interacción exposición y ladera no se observaron efectos significativos en las enzimas manganeso peroxidasa, ureasa y fosfatasa ácida.

La carboximetilcelulasa mostró efectos significativos $(P<0,001)$ en la interacción estacionalidad y exposición, con los mayores valores en exposición $\mathrm{NE}$ en invierno $\left(6,2 \pm 1,4 \mu\right.$ moles $\mathrm{g}^{-1} \mathrm{~h}^{-1}$ de glucosa) (cuadro 2). En la $\beta$-glucosidasa existieron efectos significativos en la exposición, con una mayor actividad en la exposición NE, en ambas estaciones. Las interacciones triples presentaron efectos significativos en el manganeso peroxidasa, la fosfatasa ácida y la ureasa. Las enzimas manganeso peroxidasa y fosfatasa ácida presentaron mayor actividad en invierno, a diferencia de la ureasa, la cual tuvo mayor actividad en verano.

La actividad arilsulfatasa tuvo un comportamiento similar a la enzima carboximetilcelulasa, mostrando efectos significativos $(P<0,001)$ en la interacción estacionalidad y exposición, con los mayores valores en exposición NE en invierno (cuadro 2).

Correlaciones. La correlación entre las variables biológicas mostró diferencias de comportamiento entre épocas de muestreo y entre exposiciones (cuadro 3). En verano, en dos pares de variables las correlaciones fueron positivas (con un $\mathrm{r}>0,6 ; P<0,01$ ), con otros dos pares de correlaciones negativas. En invierno la correlación aumentó a doce pares siendo todas positivas $(\mathrm{r}>0,7 ; P<0,01)$ (cuadro 3). Durante la estación invernal, la hidrólisis de la fluoresceína diacetato presentó una alta correlación con varias enzimas en especial con fosfatasa ácida y arilsulfatasa.

La exposición NE tuvo un mayor número de variables correlacionadas a diferencia de la exposición SO (cuadro 4). Las correlaciones de la hidrólisis de la fluoresceína diacetato con la mayoría de las variables fueron más altas en la exposición NE que en la SO. En otros 15 pares de variables, las correlaciones se presentaron con $r>0,65$ en ambas exposiciones. De éstas, cuatro pares de correlaciones de la arilsulfatasa cambiaron de signo.

\section{DISCUSIÓN}

Biomasa microbiana. Los datos obtenidos demuestran la relación entre las características topográficas y ecológicas, así como variaciones en los regímenes de humedad y temperatura, entre estaciones, junto con algunos parámetros químicos, como el contenido de materia orgánica.

Durante el verano, en las laderas altas, una condición de mayor humedad con respecto a las laderas medias y bajas, determina una mayor actividad de la hidrólisis de la fluoresceína diacetato, debido una mayor acumulación y degradación de la materia orgánica ya que la mayor densidad de árboles proporcionan más hojarasca estimulando la 


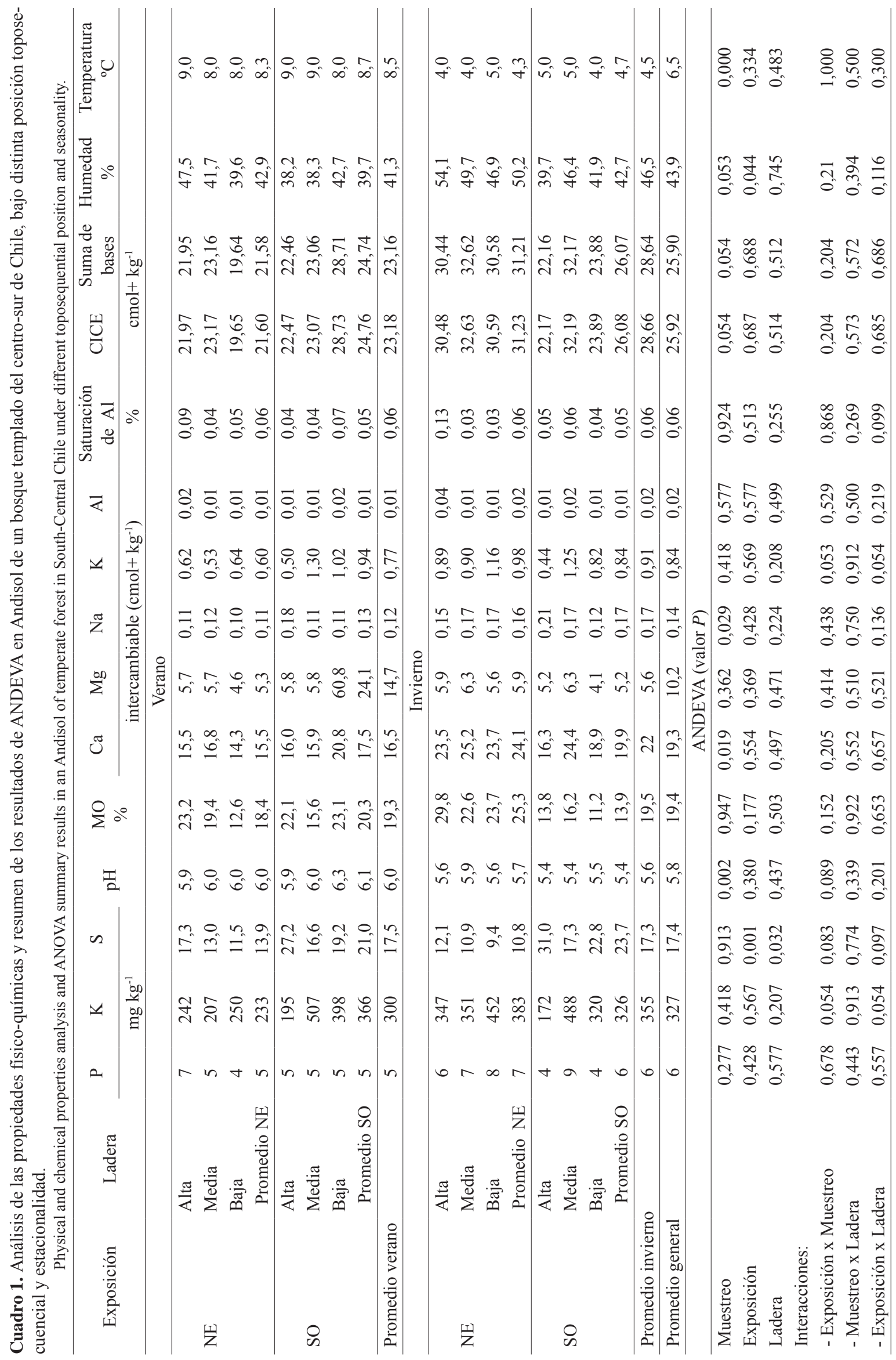




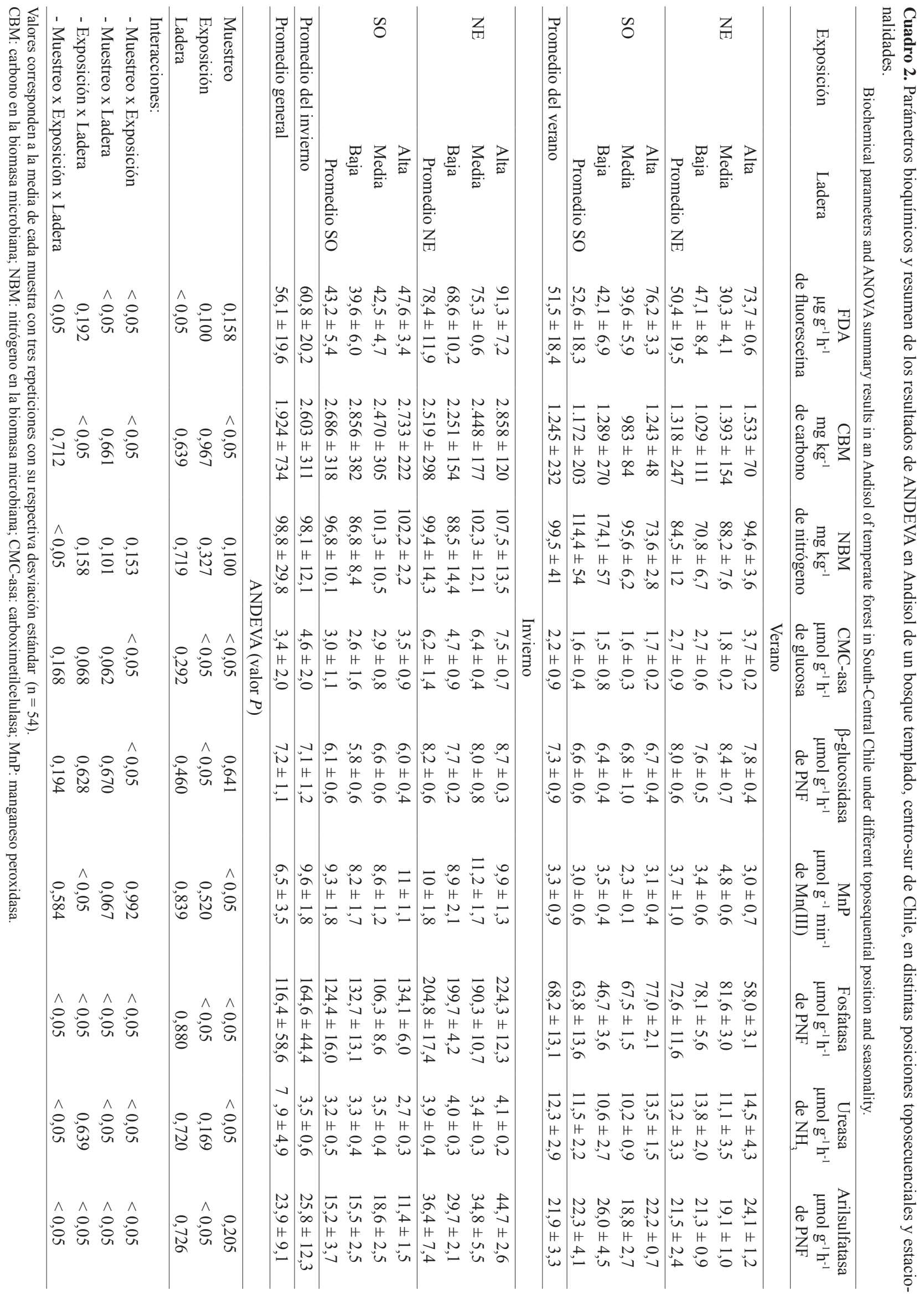


Cuadro 3. Correlación de los parámetros bioquímicos en un Andisol de un bosque templado del centro-sur de Chile, considerando el factor estacionalidad, verano (mitad inferior izquierda de la matriz) e invierno (mitad superior derecha de la matriz).

Correlations among some biochemical parameters in an Andisol of temperate forest in South-Central Chile considering the seasonal changes factor, summer (lower left half of the matrix) and winter (right upper half of the matrix).

\begin{tabular}{|c|c|c|c|c|c|c|c|c|c|}
\hline & FDA & $\mathrm{CBM}$ & NBM & CMC-asa & $\beta$-glucosidasa & $\mathrm{MnP}$ & Fosfatasa ácida & Ureasa & Aril \\
\hline FDA & - & $\mathrm{ns}$ & $\mathrm{ns}$ & $0,86^{* * *}$ & $0,87 * * *$ & $\mathrm{~ns}$ & $0,92 * * *$ & $0,57^{*}$ & $0,92 * * *$ \\
\hline $\mathrm{CBM}$ & $\mathrm{ns}$ & - & ns & $\mathrm{ns}$ & ns & $\mathrm{ns}$ & ns & ns & $\mathrm{ns}$ \\
\hline NBM & $\mathrm{ns}$ & $\mathrm{ns}$ & - & ns & 0,47 & $0,56^{*}$ & ns & ns & $\mathrm{ns}$ \\
\hline CMC-asa & $\mathrm{ns}$ & $\mathrm{ns}$ & ns & - & $0,82 * * *$ & $\mathrm{~ns}$ & $0,83 * * *$ & $0,53 *$ & $0,83 * * *$ \\
\hline$\beta$-glucosidasa & $\mathrm{ns}$ & $\mathrm{ns}$ & ns & ns & - & $\mathrm{ns}$ & $0,87 * * *$ & $0,80^{* * *}$ & $0,95 * * *$ \\
\hline $\mathrm{MnP}$ & $\mathrm{ns}$ & $0,47^{*}$ & ns & ns & $0,58^{*}$ & - & ns & ns & ns \\
\hline Fosfatasa ácida & $\mathrm{ns}$ & ns & $-0,76^{* * *}$ & $\mathrm{~ns}$ & $0,47^{*}$ & ns & - & $0,67 * *$ & $0,89 * * *$ \\
\hline Ureasa & $0,50^{*}$ & $\mathrm{~ns}$ & $\mathrm{~ns}$ & $0,64 * *$ & ns & ns & $\mathrm{ns}$ & - & $0,74 * * *$ \\
\hline Aril & $\mathrm{ns}$ & ns & $0,67 * *$ & $\mathrm{~ns}$ & ns & ns & $-0,60^{* *}$ & ns & - \\
\hline
\end{tabular}

$*=P<0,05 ; * *=P<0,01 ; * * *=P<0,001 ;$ ns $=$ no significativo.

FDA: hidrólisis fluoresceína diacetato; CBM: carbono en la biomasa microbiana; NBM: nitrógeno en la biomasa microbiana; CMC-asa: carboximetilcelulasa; MnP: manganeso peroxidasa; Aril: arilsulfatasa.

Cuadro 4. Correlación de los parámetros bioquímicos en un Andisol de un bosque templado del centro-sur de Chile considerando el factor exposición, exposición NE (mitad inferior izquierda de la matriz) y SO (mitad superior derecha de la matriz).

Correlations among some biochemical parameters in an Andisol of temperate forest in South-Central Chile considering the seasonal changes factor, summer (lower left half of the matrix) and winter (right upper half of the matrix).

\begin{tabular}{|c|c|c|c|c|c|c|c|c|c|}
\hline & FDA & CBM & NBM & $\begin{array}{c}\text { CMC- } \\
\text { asa }\end{array}$ & $\beta$-glucosidasa & $\mathrm{MnP}$ & $\begin{array}{c}\text { Fosfatasa } \\
\text { ácida }\end{array}$ & Ureasa & Aril \\
\hline FDA & - & ns & ns & ns & ns & ns & ns & $0,54 *$ & ns \\
\hline NBM & $0,57 *$ & $0,73 * *$ & - & ns & ns & ns & ns & ns & $0,56^{*}$ \\
\hline CMC-asa & $0,88 * * *$ & $0,91 * * *$ & $0,65 * *$ & - & ns & $0,66 * *$ & $0,67 * *$ & $-0,57^{*}$ & ns \\
\hline$\beta$-glucosidasa & ns & ns & $0,64 * *$ & ns & - & ns & ns & ns & ns \\
\hline $\mathrm{MnP}$ & $0,56^{*}$ & $0,87 * * *$ & $0,60 * *$ & $0,80 * * *$ & $\mathrm{~ns}$ & - & $0,88 * * *$ & $-0,87 * * *$ & $-0,65^{* *}$ \\
\hline Fosfatasa ácida & $0,65 * *$ & $0,93 * * *$ & $0,53 *$ & $0,84 * * *$ & ns & $0,90 * * *$ & - & $-0,82 * * *$ & $-0,79 * * *$ \\
\hline Ureasa & $-0,48 *$ & $-0,80 * * *$ & ns & $-0,69 * *$ & $\mathrm{~ns}$ & $-0,87 * * *$ & $-0,88 * * *$ & - & $0,76^{* * *}$ \\
\hline Aril & $0,82 * * *$ & $0,93 * * *$ & $0,74 * * *$ & $0,93 * * *$ & $0,47 *$ & $0,75 * * *$ & $0,87 * * *$ & $-0,68 * *$ & - \\
\hline
\end{tabular}

$*=P<0,05 ; * *=P<0,01 ; * * *=P<0,001 ;$ ns $=$ no significativo.

FDA: hidrólisis fluoresceína diacetato; CBM: carbono en la biomasa microbiana; NBM: nitrógeno en la biomasa microbiana; CMC-asa: carboximetilcelulasa; MnP: manganeso peroxidasa; Aril: arilsulfatasa.

biomasa microbiana del suelo. El aumento de la biomasa microbiana en la estación invernal se relaciona directamente con el contenido de microorganismos en el material vegetal fresco acumulado sobre la superficie por la presencia de sustratos fácilmente disponibles.

$\mathrm{Al}$ contrastar las toposecuencias y período estacional, se observa en la exposición NE un aumento considerable de la biota activa en invierno, en cada uno de los niveles toposecuenciales; la temperatura y las precipitaciones son dos de los principales factores que regulan la actividad microbiana, ya que según Ushio et al. (2008) la descomposición de los residuos orgánicos se incrementa en estaciones frías en suelos fértiles. La mayor densidad de árboles genera un mayor aporte de hojarasca, la que favorece la retención de agua en el suelo, aumentando los niveles de humedad edáfica, la que junto con un elevado porcentaje de materia orgánica favorece la activación y un aumento de la biomasa microbiana del suelo, ya que existe una mayor fuente de energía y de nutrientes, según la cantidad y calidad del sustrato presente en el suelo, lo que contribuye al desarrollo y actividad biológica (Li et al. 2004).

En cuanto a la relación existente entre las variables biológicas, destaca la correlación positiva de la hidrólisis de la fluoresceína diacetato con la mayoría de las variables, en la exposición NE $(P<0,01)$, lo que permite suponer que los microorganismos dependen de que las actividades enzimáticas liberen nutrientes para poder realizar su actividad metabólica (Peña et al. 2005).

Con respecto al carbono en la biomasa microbiana, no existe variación entre posiciones toposecuenciales, debido 
al permanente aporte y a la misma naturaleza del material orgánico acumulado. Sin embargo, se observa una variación significativa entre estaciones, lo cual se relaciona con variaciones temporales de la temperatura y la humedad del suelo y, por tanto, a cambios en la comunidad microbiana. Esto permite asumir una mayor proliferación de biomasa fúngica en la ladera alta, debido a los mayores índices de materia orgánica y de humedad, lo cual permite degradar más eficientemente los compuestos carbonados, que son inmovilizados por los hongos.

Hay una alta correlación del carbono en la biomasa microbiana con la carboximetilcelulasa y manganeso peroxidasa en la exposición NE, al igual que la arilsulfatasa, considerada un indicador indirecto de actividad fúngica (Alexander 1980, Alvear et al 2007), debido al aumento de la materia orgánica, lo que favorece la proliferación de hongos en esta exposición. Estas diferencias se centran en la descomposición de la materia orgánica la cual alberga una gran diversidad de microorganismos, lo que influencia la estructura de las comunidades descomponedoras de la composición química de los desechos orgánicos (Bastida et al. 2008).

Aunque se establece que el aumento de carbono en la biomasa microbiana implica la disponibilidad relativa mayor de sustratos frescos o proporción de sustratos orgánicos disponibles, la lluvia favorecería la biodegradación y solubilidad de compuestos orgánicos, por tanto un incremento significativo de las precipitaciones, durante el invierno, podría estar relacionado con un aumento en el contenido de carbono en la biomasa microbiana.

El nitrógeno en la biomasa microbiana no presenta efectos significativos, lo que indica que los ciclos de los nutrientes son muy conservadores en nitrógeno y que la cantidad que es continuamente mineralizada se acumula e inmoviliza, y muy poco se pierde por lavado o desnitrificación, lo que indicaría una mayor tasa de mineralización de nitrógeno a partir de la materia orgánica. Sin embargo, la exposición NE presenta una disminución en el contenido de nitrógeno en la biomasa microbiana durante el invierno, desde la ladera alta a la baja, producto de una disminución de los niveles de humedad y materia orgánica. De esta manera, el proceso de mineralización se ve favorecido por cambios frecuentes entre estado seco y húmedo del suelo (Alexander 1980).

Actividades enzimáticas. La influencia de la posición de la pendiente tiende a crear condiciones ambientales en el suelo que pueden afectar la estructura y función de comunidades microbianas y la actividad de enzimas hidrolíticas.

La actividad carboximetilcelulasa es una evaluación indirecta de la actividad de un determinado grupo de microorganismos, ya que participa en la transformación de los biopolímeros, incluidos los polímeros de pared celular de los vegetales tales como la celulosa y hemicelulosa, junto con otros polisacáridos disponible en el mantillo y en los suelos (Alvear et al. 2008). Esta enzima aumenta su actividad en invierno, debido a la mayor proporción de elementos vegetales lábiles provenientes del dosel, los cuales son rápidamente degradados debido a la mayor humedad registrada en esta estación en la exposición NE, ya que la capa de hojarasca está más expuesta a cambios en las condiciones medioambientales que los más protegidos de humus y la capa de suelo mineral, lo que indica que es el principal factor microclimático que regula la actividad de la enzima; además, el aumento de la población microbiana, específicamente hongos activos, genera una mayor eficiencia por parte de los hongos en la metabolización de compuestos carbonados (Alvear et al. 2007). La mayor acumulación de materia orgánica en invierno favorece la secreción de la enzima, situación similar a la planteada por Wittmanna et al. (2004), quienes mencionan la correlación que existe entre la acumulación de materia orgánica y el aumento de la actividad carboximetilcelulasa. Esto se ve reflejado en la alta correlación de esta enzima con la arilsulfatasa en invierno y, además, la significativa correlación existente entre ambas enzimas en la exposición NE, favorecida por el aumento de la materia orgánica.

Adiferencia de la carboximetilcelulasa, la $\beta$-glucosidasa no presenta variaciones significativas en sus niveles de actividad entre estaciones y exposiciones, lo que permite suponer que la calidad del sustrato con respecto a los requerimientos de la enzima, no varía, así como en la toposecuencia. La presencia de un dosel arbóreo cerrado, que limita la penetración de la radiación solar y mantiene niveles de humedad y una temperatura adecuada en la hojarasca para el proceso de degradación, se relaciona con una nula variación en la tasa de liberación de sustratos (Weedon et al. 2009). Por otro lado, una fracción significativa de la enzima a menudo no es extraíble debido a la unión a componentes del suelo, no detectándose efectos significativos. Sin embargo, se presenta una alta relación entre esta enzima y la carboximetilcelulasa en invierno ( $\mathrm{r}$ $=0,82 ; P<0,001)$ lo que da cuenta de la estrecha relación entre ambas actividades, ya que el producto de la reacción catalizada por la carboximetilcelulasa sirve como sustrato para la $\beta$-glucosidasa (Turner et al. 2002).

Las enzimas ligninolíticas, tales como la manganeso peroxidasa, son producidas exclusivamente por especies saprotróficas de hongos Basidiomycota, por lo que la actividad de esta enzima puede ser una evaluación indirecta de la actividad de un determinado grupo de microorganismos en el suelo en respuesta a diferentes factores ambientales o perturbaciones (Hofrichter 2002, Alvear et al. 2008).

En verano, los niveles de humedad, tanto ambiental como del suelo, no habrían sido suficientes como para permitir la proliferación de esta clase de hongos, capaces de secretar en grandes cantidades la enzima. En invierno, debido a un aumento de la pluviosidad, lo que se relaciona con una diminución del $\mathrm{pH}$ del suelo, el mayor contenido de humedad, estimula la presencia de esta clase de hongos (Hofrichter 2002), aumentando los niveles de secreción de la enzima manganeso peroxidasa en ambas exposiciones, 
degradando los compuestos lignolíticos provenientes del fuste, corteza, ramas, ramillas y hojas (Alvear et al. 2007). Esto podría relacionarse con las fases iniciales de la degradación de la hojarasca y la presencia de un mayor aporte de sustrato, ya que fue significativamente menor la actividad en verano (Valášková et al. 2007).

La correlación entre el carbono en la biomasa microbiana y las enzimas relacionadas al ciclo del carbono en ambas estaciones no son significativas o son muy bajas, al no existir las condiciones más adecuadas para la proliferación de hongos, principales secretores de estas enzimas, mientras que los niveles de correlación en ambas exposiciones son significativos, a excepción de la $\beta$-glucosidasa. La correlación entre el carbono en la biomasa microbiana y la manganeso peroxidasa es altamente significativa y positiva en ambas exposiciones, NE $(\mathrm{r}=0,87 ; P<0,001)$ y $\mathrm{SO}(\mathrm{r}=0,93 ; P<0,001)$, lo que indicaría que la naturaleza de los residuos vegetales aportados al suelo, dado el alto contenido de lignina por parte de especies latifoliadas perennes como A. punctatum.

Los niveles de actividad de fosfatasa ácida son mayores en invierno, debido al pH más ácido, situándose dentro del rango óptimo de $\mathrm{pH}$ para la actividad de esta enzima, y con un mayor contenido de humedad (Criquet et al. 2004), lo que genera las mejores condiciones para la actividad fúngica, incluyendo a micorrizas y hongos saprófitos, siendo los principales agentes en secretar esta enzima. En el mismo sentido, Alvear et al. (2008) señalan que los niveles óptimos de esta enzima se observan con un $\mathrm{pH} 5,5$, valor muy similar a los registrados durante invierno; junto con mejores índices de capacidad de intercambio catiónico efectiva, lo cual favorece una mayor actividad microbiana (hidrólisis de la fluoresceína diacetato). El pH del mantillo también puede influir en la densidad, composición y el metabolismo de la población microbiana, y por lo tanto en la actividad de la enzima (Criquet et al. 2004).

Durante el verano la menor actividad fosfatasa desciende por efecto de la mayor temperatura y menor humedad del suelo. En la exposición SO, los mayores índices de actividad se obtienen en la ladera alta y media, debido al alto contenido de materia orgánica. La materia orgánica contiene grandes cantidades de sustratos enzimáticos, incluyendo los de fosfatasas las que liberan nutrientes minerales como iones de ortofosfato. Por tanto, estos niveles de actividad, en concordancia con Alvear et al. (2007, 2008), se relacionan directamente con una mayor actividad de la biota activa del suelo por la cantidad de sustratos disponibles, lo que se corrobora con la alta correlación en invierno.

La actividad ureasa se ve influenciada por cambios en los regímenes de humedad y temperatura, siendo superior durante el periodo estival. Resulta interesante señalar, en concordancia con Moyo et al. (1989), que a medida que aumenta la temperatura del suelo, la ureasa, también aumenta en su actividad. Con respecto a la humedad, Ross et al. (1984) determinan que la actividad ureasa está correla- cionada negativamente con la humedad del suelo, lo que se ve reflejado en invierno, al disminuir la biomasa bacteriana, en comparación al verano, producto de que el suelo se torna más ácido debido a las abundantes lluvias. Por otro lado, se sugiere que una disminución de nitrógeno en su forma más lábil y un aumento en las más recalcitrantes es la posible razón de una reducción en la actividad durante la estación invernal, lo cual se relaciona con la naturaleza de los residuos depositados sobre la superficie del suelo. La correlación negativa en la exposición NE a positiva en la exposición SO, entre ureasa y la arilsulfatasa, hace mención a que la biomasa bacteriana, capaz de secretar la enzima ureasa, principalmente, disminuye en la otra exposición, lo cual se relaciona con la producción de hojarasca y con las condiciones de nutrición (Kang et al. 2009).

La actividad arilsulfatasa juega un importante rol en los procesos en que el azufre orgánico del suelo es mineralizado, sobre todo en suelos más frescos y húmedos que en estaciones más secas, manifestando una estrecha relación entre la mineralización de compuestos orgánicos y la actividad enzimática del suelo. Cabe mencionar que el aumento de la humedad durante el periodo invernal y del contenido de materia orgánica, en la exposición NE, contribuye a que esta enzima sea secretada en altos niveles por la biota activa del suelo, principalmente por la biomasa fúngica (Prietzel 2001), ya que una disminución del pH del suelo genera una condición más óptima para que prolifere este tipo de microorganismos, lo que es corroborado por las altas correlaciones entre estas variables. Por otro lado, la demanda de azufre por las plantas y los microorganismos del suelo puede deberse al estímulo en la síntesis de esta enzima. Además, la fracción de arcilla del suelo puede aumentar la actividad de la enzima y reflejar la abundancia de ésteres sulfatados obtenidos de materiales vegetales en proceso de descomposición, cuerpos de los animales y los excrementos en esta fracción (Kang et al. 2009).

Con respecto a los tres pares de correlaciones de la arilsulfatasa que cambiaron su signo de positivo a negativo, se sugiere que existen cambios en la composición y cantidad de la biomasa fúngica. Hansen y Coleman (1998) demuestran como los cambios físicos en la hojarasca mixta depositada en el suelo pueden alterar la actividad de la comunidad descomponedora y las tasas de descomposición asociadas.

\section{CONCLUSIONES}

Las actividades biológicas fueron mayores en invierno, en ambas exposiciones, para el carbono en la biomasa microbiana, manganeso peroxidasa y fosfatasa ácida, dada una condición de $\mathrm{pH}$ y humedad más favorable, así como la mayor acumulación y aporte, por parte de distintas especies forestales, de material vegetal. La actividad carboximetilcelulasa y arilsulfatasa, sólo fue mayor para la exposición NE en la estación invernal, lo que permite concluir que hay variaciones en la población microbiana 
y, por tanto, en la calidad del sustrato. La actividad ureasa fue la única enzima con mayores niveles de actividad en verano, debido a que la enzima se activó con un aumento de la temperatura del suelo. La degradación de la hojarasca se relacionó con la humedad y la temperatura del suelo y la precipitación, afectando la disponibilidad de sustratos y niveles de actividad enzimática. La definición de las variables biológicas y el rango de actividad que éstas pueden alcanzar, tienen una estrecha relación con la dinámica de nutrientes y las propiedades físico-químicas del suelo en ecosistemas relictos.

\section{AGRADECIMIENTOS}

Al Proyecto DI-10-0023 de la Dirección de Investigación de la Universidad de La Frontera.

\section{REFERENCIAS}

Alexander M. 1980. Introducción a la microbiología del Suelo. México DF, México. AGT. 483 p.

Alvear M, F Reyes, A Morales, C Arriagada, M Reyes. 2007. Actividad biológica y agregados estables al agua en dos tipos de formaciones vegetales de un bosque templado del Centro-Sur de Chile con perturbación antrópica. Ecología Austral 17: 113-122.

Alvear M, M Astorga, F Reyes. 2008. Efecto de los residuos vegetales provenientes de dos tratamientos silvícolas en una plantación de Pinus radiata D. Don sobre los cambios estacionales de las actividades biológicas del suelo. Revista de la Ciencia del Suelo y Nutrición Vegetal 8(1): 14-27.

Armesto JJ, C Smith-Ramírez, M Carmona, JL Celis-Diez, I Díaz, A Gaxiola, AG Gutiérrez, M Núñez-Ávila, C Pérez, R Rozzi. 2009. Old-growth temperate rain forests of South America: conservation, plant-animal interactions, and baseline biogeochemical processes. In Wirth $\mathrm{Ch}$, G Gleixner, M Heimann eds. Old-Growth Forests. Function, fate and value. Springer. p. 367-390.

Bastida F, GG Barberá, C García, T Hernández. 2008. Influence of orientation, vegetation and season on soil microbial and biochemical characteristics under semiarid conditions. Applied Soil Ecology 38: 62-70.

Burke A. 2003. How special are Etendeka mesas? Flora and elevation gradients in an arid landscape in north-west Namibia. Journal of Arid Environments 55(4): 747-764.

Criquet S, E Ferre, AM Farnet, J Le Petit. 2004. Annual dynamics of phosphatase activities in an evergreen oak litter: influence of biotic and abiotic factors. Soil Biology and Biochemistry 36(7): 1111-1118.

Diez MC, F Gallardo, G Saavedra, M Cea, L Gianfreda, M Alvear. 2006. Effect of pentachlorophenol on selected soil enzyme activities in a Chilean Andisol. Revista de la Ciencia del Suelo y Nutrición Vegetal 6(3): 40-51.

Donoso C. 1981. Tipos forestales de los bosques nativos de Chile. Santiago, Chile. Proyecto Investigación y Desarrollo Forestal FO: DP/CHI/76/003. Documento de trabajo $\mathrm{N}^{\circ} 38.70 \mathrm{p}$.

Gil-Sotres F, M Trasar-Cepeda, C Ciardi, B Ceccantti, M Leirós. 1992. Biochemical characterization of biological activity in very young mine soils. Biology and Fertility of Soils 13: 25-30.
Hansen RA, DC Coleman. 1998. Litter complexity and composition are determinants of the diversity and species composition of oribatid mites (Acari: Oribatida) in mantillobags. Applied Soil Ecology 9(1): 17-23.

Hofrichter M. 2002. Review: lignin conversion by manganese peroxidase (MnP). Enzyme and Microbial Technology 30 (4): 454-466.

Kang H, S Kang, D Lee. 2009. Variations of soil enzyme activities in a temperate forest soil. Ecological Research 24(5): 1137-1143.

Li Q, HL Allen, AG Wollum. 2004. Microbial biomass and bacterial functional diversity in forest soils: effects of organic matter removal, compaction, and vegetation control. Soil Biology and Biochemistry 36(4): 571-579.

Moyo CC, DE Kissel, ML Cabrera. 1989. Temperature effects on soil urease activity. Soil Biology and Biochemistry 21 (7): 935-938.

Peña W, M Leirós, J Briceño. 2005. Propiedades generales y bioquímicas de suelos forestales en áreas serpentinizadas de Galicia. Agronomía Costarricense 29(3): 71-78.

Prietzel J. 2001. Arylsulfatase activities in soils of the black Forest/Germany seasonal variation and effect of $\left(\mathrm{NH}_{4}\right)_{2} \mathrm{SO}_{4}$ fertilization. Soil Biology and Biochemistry 33 (10): 13171328.

Ross DJ, TW Speir, JC Cowling, KN Whale. 1984. Temporal fluctuations in biochemical properties of soil under pasture. II. Nitrogen mineralization and enzyme activities. Australian Journal of Soil Research 22: 219-242.

Sadzawka A, MA Carrasco, R Grez, ML Mora. 2004. Métodos de análisis recomendados para los suelos chilenos. Sociedad Chilena de la Ciencia del Suelo. 113 p. (Comisión de normalización y acreditación).

Schinner F, W von Mersi. 1990. Xylanase, CM-cellulase and invertase activity in soil: an improved meted. Soil Biology and Biochemistry 22(4): 511-515.

Trasar-Cepeda C, M Leirós, F Gil-Sotres. 2000. Biochemical properties of acid soils under climax vegetation (Atlantic oakwood) in an area of the European temperate-humid zone (Galicia, NW Spain): specific parameters. Soil Biology and Biochemistry 32(6): 747-755.

Turner BL, DW Hopkins, PM Haygarth, N Ostle. 2002. $\beta$-Glucosidase activity in pasture soils. Applied Soil Ecology 20(2): 157-162.

Ushio M, R Wagai, TC Balser, K Kitayama. 2008. Variations in the soil microbial community composition of a tropical montane forest ecosystem: Does tree species matter? Soil Biology and Biochemistry 40(10): 2699-2702.

Valášková V, J Šnajdr, B Bittner, T Cajthaml, V Merhautová, M Hofrichter, P Baldrian. 2007. Production of lignocellulosedegrading enzymes and degradation of leaf litter by saprotrophic basidiomycetes isolated from a Quercus petraea forest. Soil Biology and Biochemistry 39(10): 2651-2660.

Valenzuela E, S Leiva, R Godoy. 2001. Potencial enzimático de microhongos asociados a la descomposición de hojarasca de Nothofagus pumilio. Revista Chilena de Historia Natural 74: 737-749.

Vance F, P Brookes, D Jenkinson. 1987. Microbial biomass measurements in forest soils: The use of the chloroform fumigation-incubation method in strongly acid soils. Soil Biology and Biochemistry 19: 697-702.

Weedon JT, WK Cornwell, JHC Cornelissen, A Zanne, C Wirth, D Coomes. 2009. Global meta-analysis of wood decompo- 
sition rates: a role for trait variation among tree species? Ecology Letters 12(1): 45-56.

Wittmanna C, M Káhkónen, H Ilvesniemib, J Kurolaa, M Salkinoja-Salonena. 2004. Areal activities and stratification of hydrolytic enzymes involved in the biochemical cycles of carbon, nitrogen, sulphur and phosphorus in podsolized boreal forest soils. Soil Biology and Biochemistry 36(3): 425-433.

Recibido: 23.03 .10

Aceptado: 12.08 .11 
